\title{
Somatic embryogenesis in artificially pollinated seed families of 2 nd generation plus trees and cryopreservation of embryogenic tissue in Cryptomeria japonica D. Don (Sugi)
}

\author{
Toru Taniguchi*,a, Ken-ichi Konagaya, Yoshihiko Nanasato \\ Forest Bio-Research Center, Forestry and Forest Products Research Institute (FFPRI), 3809-1 Ishi, Hitachi, Ibaraki 319-1301, \\ Japan \\ *E-mail: toru.t@affrc.go.jpＴel: +81-19-688-4518 Fax: +81-19-694-1715
}

Received October 30, 2019; accepted February 20, 2020 (Edited by N. Onishi)

\begin{abstract}
Cryptomeria japonica D. Don (common name is Sugi or Japanese cedar) is the most important forestation tree species in Japan, and 2nd generation plus trees with superior traits have been selected by breeding projects. Biotechnological approaches such as genetic transformation and genome editing are expected to accelerate to add useful traits (e.g., no-pollen traits) to superior trees in short time. To develop a platform for genetic transformation and genome editing of $C$. japonica superior trees, this study investigated the embryogenic potential of 2 nd generation plus trees and obtained good cell lines with high embryogenic potential, which could be useful material for adding new and useful traits to superior trees by genetic transformation. However, the maintenance of embryogenic cell lines is laborious, and prolonged subculture leads to a loss of embryogenesis potential. Therefore, cell lines need to be cryopreserved for long without subculture. Therefore, in this study we made a simple cryopreservation protocol suitable for most $C$. japonica cell lines. We showed that cryopreserved cells using this protocol formed somatic embryos, which were then converted to plantlets. Transgenic cells produced from cryopreserved cells expressed transgene, $g f p$. These results indicated that our cryopreservation protocol can be used for prolonged storage of genetic transformation target materials in C. japonica.
\end{abstract}

Key words: cryopreservation, Cryptomeria japonica, somatic embryogenesis.

\section{Introduction}

Cryptomeria japonica D. Don (common name is Sugi or Japanese cedar) is the most important forestation tree species in Japan, and it covers $44 \%$ (4.44 million ha) of Japanese artificial forests. It is mainly used as construction wood, and for biomass energy. C. japonica breeding project has started in the early 1950s. In the project, 1st generation plus trees with good growth traits and straight trunk form were selected mainly from artificial forests and partly from natural populations, and the total number of 1st generation C. japonica plus trees was 3,670. Currently, over $60 \%$ of seedlings used for afforestation of $C$. japonica come from seed orchards and scion gardens established by the 1st generation plus tree clones (Forest Tree Breeding Center 2017). Recently, to generate more superior trees than 1st generation plus trees, 2nd generation plus trees have been selected from progeny of 1st generation plus trees, mainly on the basis of growth, trunk form, and stiffness.

Japanese cedar pollinosis (allergic reaction to $C$. japonica pollen) is a serious issue in Japan, and 26.5\% of the Japanese population suffers from it (Nakae and Baba 2010). To address this issue, less pollen tree and no-pollen mutants were selected. To produce nopollen individuals with superior growth traits, artificial pollinations have been conducting between no-pollen mutants and plus trees. Biotechnological approaches for C. japonica breeding, such as genetic transformation and genome editing, are expected to quickly add no-pollen traits to superior $C$. japonica trees.

We developed Agrobacterium mediated genetic transformation and transgenic plant regeneration method in C. japonica for the first time (Taniguchi et al. 2008). Genetic transformation efficiency was improved by Konagaya et al. (2013a). Male sterile transgenic $C$. japonica were produced by the barnase/barstar system, and the male sterile transgenic $C$. japonica were subjected to a field trial (Konagaya et al. 2013b). In addition, recently, genome editing using CRISPR/Cas9 system was developed (Nanasato et al. manuscript in preparation).

One of our goal is to add useful traits such as no-

${ }^{a}$ Present address: Tohoku Regional Office, Forest Tree Breeding Center, FFPRI, 95 Osaki, Takizawa, Iwate 020-0621, Japan This article can be found at http://www.jspcmb.jp/

Published online June 18, 2020 
pollen to C. japonica superior trees by biotechnological approach using somatic embryogenesis system. However, in C. japonica, somatic embryogenesis system has two troublesome issues.

First, ability of somatic embryogenesis process (i.e., embryogenic tissue induction and somatic embryo formation) is genetically influenced (Park 2002). It is that the potential of somatic embryo formation differs among individuals. We examined the embryogenic potential of 1st generation plus trees (Taniguchi et al. 2008, 2012), but those of 2 nd generation plus trees are unknown. Therefore, we should determine the embryogenic potential of 2 nd generation $C$. japonica plus trees.

Second, it is difficult to routinely use embryogenic tissue for genetic transformation. That is because a suitable season for embryogenic cell induction is limited to early July. Moreover, prolonged subculture leads to a loss of embryogenic potential (Breton et al. 2006). Therefore, we should develop a cryopreservation protocol for C. japonica embryogenic tissue that has high potential of somatic embryo formation.

In this study, to develop a platform for genetic transformation and genome editing of superior C. japonica trees, we surveyed the embryogenic potential of 2 nd generation plus trees, and develop a cryopreservation protocol for C. japonica embryogenic tissue. Achievement in this paper should be helpful for adding useful traits to $C$. japonica superior trees via biotechnological approaches.

\section{Materials and methods}

\section{Plant materials}

C. japonica individuals planted at the Forest Tree Breeding Center, FFPRI in Hitachi, Ibaraki, Japan were used in this research. Branch tips (ca. $20 \mathrm{~cm}$ long) were dipped in or sprayed with $100 \mathrm{mgl}^{-1}$ aqueous solution of gibberellic acid $\left(\mathrm{GA}_{3}\right.$; Kyowa-Hakko, Tokyo, Japan) in early July and early August to promote the male and female strobili, respectively. The next year after $\mathrm{GA}_{3}$ treatment artificial pollination was performed in the middle of March, and immature green cones were collected in early July.

\section{Culture conditions}

Cultures for the induction and maintenance of embryogenic tissue and maturation of somatic embryos were kept in the dark at $25^{\circ} \mathrm{C}$. For the regrowth of cryopreserved cells, cultures were also kept in the dark at $25^{\circ} \mathrm{C}$. Conversion of somatic embryo to plantlets on germination medium (Taniguchi et al. 2008) was performed under a $16 / 8$-h (day/night) photoperiod at $25^{\circ} \mathrm{C}$ with light provided by cool-white fluorescent lamps at an intensity of $70 \mu \mathrm{mol} \mathrm{m}^{-2} \mathrm{~s}^{-1}$.

\section{Embryogenic tissue induction and somatic embryogenesis}

Embryogenic tissue induction was performed as previously described (Taniguchi et al. 2004, 2008). Briefly, immature green cones were washed in running water with a neutral detergent and surface sterilized with $70 \%$ ethanol for $10 \mathrm{~min}$, and the pale-yellow seeds were extracted from the cones. These seeds were sterilized with $70 \%$ ethanol for $1 \mathrm{~min}$ and $6 \% \mathrm{H}_{2} \mathrm{O}_{2}$ for $5 \mathrm{~min}$. Immature seed explants (megagametophytes containing pre-cotyledonary zygotic embryo [zygotic embryos before cotyledonary primordium differentiation]) were removed aseptically from immature seeds using a stereo microscope and placed horizontally on $1 / 2 \mathrm{MD}^{\prime}$ medium (referred to as IM medium in Taniguchi et al. 2008). After 4 weeks of culture, immature seed explants were transferred onto $1 / 2 \mathrm{MD}$ medium (referred to as MM medium in Taniguchi et al. 2008) for subculture, and proliferated cells were subcultured on fresh 1/2 MD medium at 2-week intervals.

\section{Embryonic ability Survey}

In 2016, embryogenesis ability was estimated in 16 seed families obtained by artificial pollination using four 2 nd generation plus tree clones (clones \#208, \#209, \#83, and \#31) as the maternal parent and four other 2 nd generation plus tree clones (clones \#206, \#200,\#217, and \#214) as the paternal parent (Supplementary Figure S1). In 2017 and 2018, 9 seed families (clones \#189, \#190, and \#193 as the maternal parent; clones \#213,\#199, and \#219 as the paternal parent) and 16 seed families (clones \#11, \#22, \#78, and \#86 as the maternal parent; $\# 26$, \#42, \#88, and \#94 as the paternal parent), respectively, were used to estimate embryogenesis ability (Supplementary Figures S2, S3).

Each year, 50 immature seed explants per seed family were cultured for embryogenic tissue induction. To estimate the embryogenic ability of each embryogenic cell line, proliferated embryogenic tissues on $1 / 2 \mathrm{MD}$ medium were transferred to COM medium (referred to as somatic embryo maturation medium in Taniguchi et al. 2008). Five clumps of ca. $50 \mathrm{mg}$ (Fresh weight (FW)) of embryogenic tissue were cultured in one dish containing COM medium. After 6 weeks of culture, we counted number of induced embryos with cotyledon per dish. This experiment was mainly repeated thrice during 3 to 5 months after the initial culture, and the embryogenic ability of each cell line was expressed as the mean number of somatic embryos formed per dish.

\section{Embryogenic tissue cryopreservation}

Exponentially growing 1-week-old embryogenic tissue on $1 / 2 \mathrm{MD}$ medium were suspended in cryoprotectant solution (LSP solution: $1 / 2 \mathrm{MD}$ containing $2 \mathrm{M}$ glycerol, $0.4 \mathrm{M}$ sucrose, and $1 \mathrm{gl}^{-1}$ proline, modified from LS solution of Sakai et al. 1991) at a cell density of $500 \mathrm{mg}(\mathrm{FW})$ per $\mathrm{ml}$ and incubated for $90 \mathrm{~min}$ at room temperature with reciprocal shaking at 60 $\mathrm{rpm}$. Then, $0.3,0.9$, or $1.5 \mathrm{ml}$ aliquots of cell suspension were transferred into $2 \mathrm{ml}$ cryovials (Nalgene Cryoware Cryogenic 
Vials, Thermo Fisher Scientific, MA, USA); the cell mass contained in the $0.3,0.9$, and $1.5 \mathrm{ml}$ aliquots was 150,450 , and $750 \mathrm{mg}$, respectively. The cryovial lids were sealed with polytetrafluoroethylene (PTFE) tape with a width of $13 \mathrm{~mm}$. For precooling, the cryovials containing cell suspension were put into an expanded polystyrene (EPS) tube container with 50 wells (Tube Holder SD-14, Maruemu Co., Ltd., Osaka, Japan) and the tube container was placed in a freezer at a temperature of $-30^{\circ} \mathrm{C}$, and was left for $6 \mathrm{~h}$. The cell suspension were reached to a temperature of $-30^{\circ} \mathrm{C}$ in $2 \mathrm{~h}$ with a cooling rate of ca. $0.45^{\circ} \mathrm{C} \mathrm{min}{ }^{-1}$; the temperature of cell suspension was measured with a data logger (ZR-RX40, Omron, Kyoto, Japan) equipped with a temperature sensor (Type T, Taiyo Keiki, Tokyo, Japan). After precooling, the cryovials were immediately plunged into liquid nitrogen (LN) and left for at least $1 \mathrm{~h}$.

To increase the success frequency of cryopreservation, we examined the effect of cell mass on the regrowth of cryopreserved cells using four cell lines, including two recalcitrant cell lines (10A-4-22, 12-2-16, 12-5-6, and 12-7-2).

\section{Thawing and regrowth of cryopreserved cells}

To thaw frozen cell suspension, the cryovial was soaked in a $40^{\circ} \mathrm{C}$ water bath for $2 \mathrm{~min}$, and then, cell suspension in a cryovial was poured onto a double-layered filter paper on $1 / 2 \mathrm{MD}$ medium. One day later, the upper filter paper with cells was transferred to fresh $1 / 2 \mathrm{MD}$ medium and cultured for cell regrowth, and 4 weeks after thawing, images of cultures were taken, and the fresh weighs of cultures measured.

\section{Observation of cryopreserved embryogenic tissue by FDA staining}

To examine cell viable, sample of cultures before and after cryopreservation were stained with $0.5 \%$ fluorescein diacetate (FDA) (Widholm 1972) and observed under a confocal microscope (TCS SPE system, Leica Microsystems, Wetzlar, Germany).

\section{GFP gene transformation}

We conducted a transformation experiment by the methods described by Konagaya et al. (2013a) using Agrobacterium (GV3101/pMP90) carrying a binary vector, pZmUbi-GFPDt. pZmUbi-GFP-Dt was derived from UbiP-sGFP(S65T)/ HygR (Taniguchi et al. 2008) and contains a selection marker $h p t$ and a reporter gene $g f p$. To construct pZmUbi-GFP-Dt, the NPTII cassette (Pmel-Clal fragment) was excised from UbiP-sGFP(S65T)/HygR, and an Arabidopsis HSP terminator (Nagaya et al. 2009) was inserted between sGFP(S65T) and the Nos terminator. pZmUbi-GFP-Dt was transformed to embryogenic tissues that had been cryopreserved for 15 months. In transformation experiment, Agrobacterium was eliminated by $10 \mathrm{mg} \mathrm{ml}^{-1}$ meropenem and transformed tissues were selected by $10 \mathrm{mg} \mathrm{ml}^{-1}$ hygromycin. After 3 years of subculture on $1 / 2 \mathrm{MD}$ medium, the transformed tissues were again cryopreserved. After14 months, the cryopreserved transgenic tissues were thawed and then subcultured on
1/2 MD medium. Green fluorescent protein (GFP) expression of transformed tissues was observed under a fluorescence stereomicroscopy (MZ FLIII; Leica Microsystems).

\section{Results and discussion}

\section{Embryogenic tissue induction}

From 2016 to 2018, 1857 immature seed explants (except those with microbial contamination), which were collected from 41 artificially pollinated seed families of 2 nd generation C. japonica plus trees, were cultured for embryogenic tissues induction. Embryogenic tissue of C. japonica was white to translucent, moist and mucilaginous, and comprised small, dense embryonic cells and elongated, vacuolated suspensor cells (Taniguchi and Kondo 2000), like in other conifers (Jain et al. 1995). The embryogenic tissue induction rate (i.e., the percentage of explants forming embryogenic tissue from cultured explants 3 months after the initial culture) in each of the 41 artificially pollinated seed families varied from 3.3 to $86.0 \%$ with mean of $38.4 \%$ (Figure 1 ). The embryogenic tissue induction rate of 1 st generation plus trees ranged from 3.4 to $82.0 \%$ with mean of $45.6 \%$ in the open pollinated seed family (Taniguchi and Kondo 2000) and from 10 to $80 \%$ with mean of $46.6 \%$ in the artificially pollinated seed family (Taniguchi et al. 2012). These results indicated that the embryogenic tissue induction rate range is comparable between 1st generation plus trees and 2nd generation plus trees, although the mean induction rate of 2 nd generation plus trees is lower compared with 1st generation plus trees. Supplementary Figures S1, S2, S3 present the induction rate in each seed family tested.

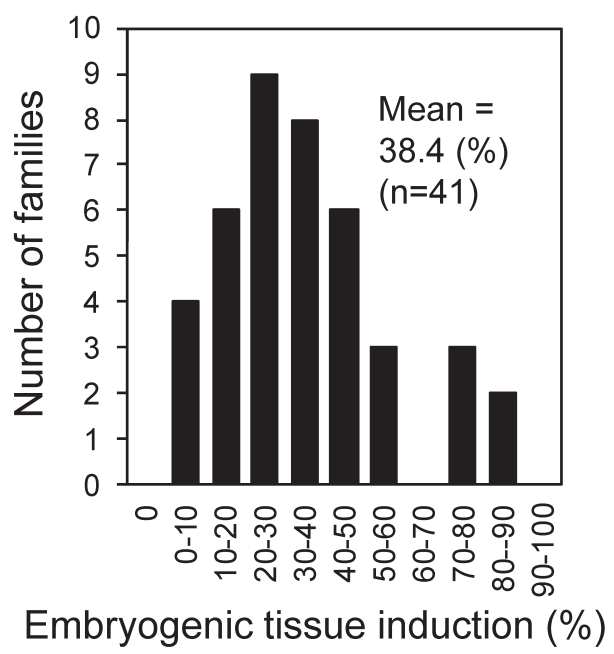

Figure 1. Frequency distribution of embryogenic tissue induction (\%) in each seed family of Cryptomeria japonica 2 nd generation plus trees. In each seed family 50 explants were cultured for embryogenic tissue induction. From 2016 to 2018, 41 artificially pollinated seed families were used for embryogenic tissue induction, and induction frequencies were determined 3 months after the initial culture. 


\section{Somatic embryo formation}

All of embryogenic cell lines (661) obtained in 2016, 2017 and 2018 were cultured on somatic embryo induction medium (COM medium). Figure 2 presents the frequency distribution of the number of somatic

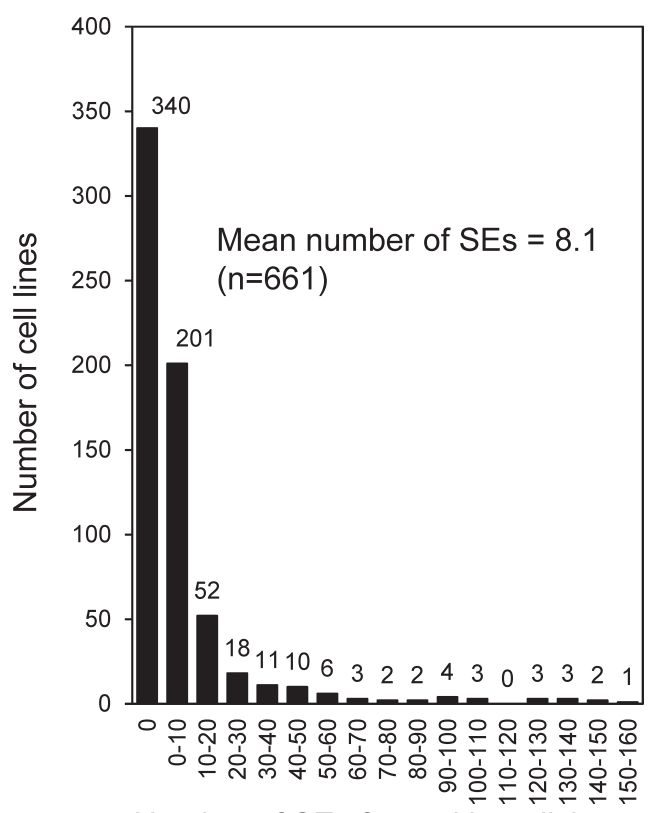

Number of SEs formed in a dish

Figure 2. Frequency distribution of the number of somatic embryos formed per dish in each cell line of Cryptomeria japonica 2 nd generation plus trees. Embryogenic cell lines $(n=661)$ induced from 41 seed families were used for somatic embryos induction, and the number of somatic embryos induced was determined after 6 weeks of culture. SE, somatic embryo. embryos formed in each cell lines. In the 41 artificially pollinated seed families of 2 nd generation plus tree, somatic embryos were formed from 321 (48.6\%) of 661 cell lines, with a mean of 8.1 somatic embryos formed per dish. In 1st generation plus tree, somatic embryos were formed 227 (64.7\%) of 351 cell lines, with a mean of 11.1 somatic embryos formed per dish (Taniguchi et al. 2012). The number of somatic embryos formed from the cell lines in each seed family varied greatly from 0 to 46.1 (Supplementary Figures S1, S2, S3), indicating that somatic embryo formation ability in $C$. japonica is genetically controlled, like in other conifers, such as Picea glauca (Park et al. 1994) and Pinus sylvestris (Niskanen et al. 2004).

\section{Embryogenic tissue cryopreservation}

Ogawa et al. (2012) reported high throughput cryopreservation protocol of plant cell cultures. This protocol was simple method that did not require a timeconsuming and cumbersome procedure like that used in many other conifer (Häggman et al. 1998) (i.e., coldhardening for 1 or 2 weeks and drop-wise addition of a cryoprotective solution containing dimethyl sulfoxide) and an expensive programmable freezer. This protocol is applicable in some plant species (A. thaliana, Daucus carota, Lotus japonicus, Nicotiana tabacum, and Oryza sativa). The protocol comprises a cryoprotection step (cells are treated with a cryoprotectant solution) and a prefreezing step (sample vials are placed in a thick, expanded polystyrene container and kept for $1-8 \mathrm{~h}$ at $-30^{\circ} \mathrm{C}$ to slowly cool the cells). After these two steps,

\section{Before cryopreservation}

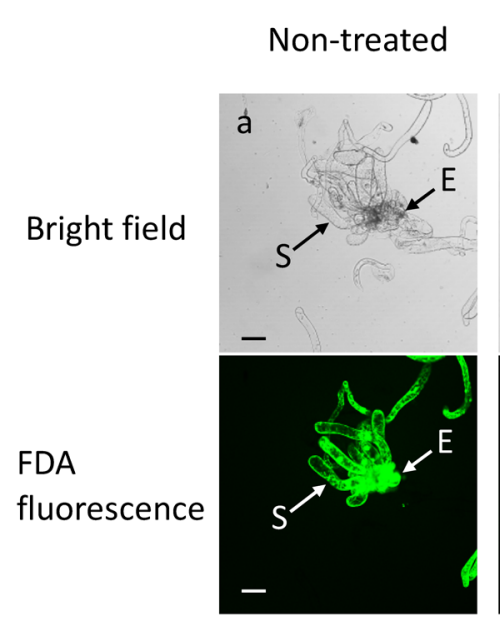

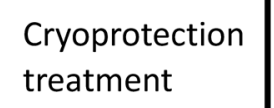

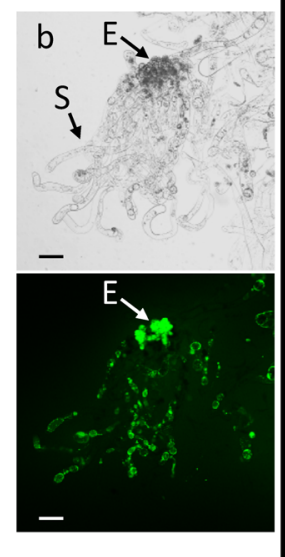

\section{After cryopreservation}

Immediately after thawing

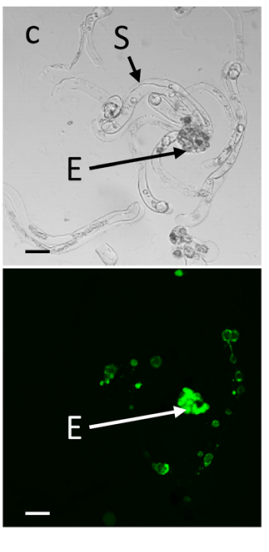

One day after thawing

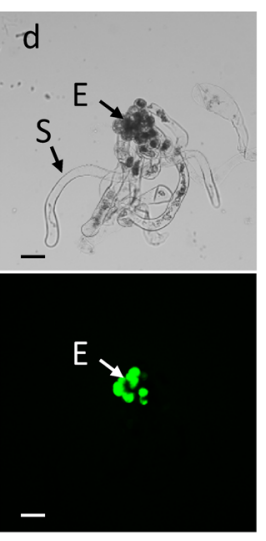

Six days after thawing

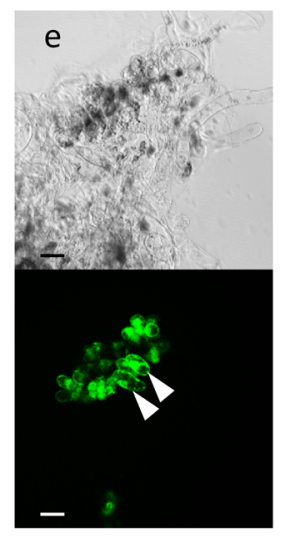

Figure 3. FDA staining of Cryptomeria japonica embryogenic tissue before and after cryopreservation. Embryonic and suspensor cells emitted FDA signals (green fluorescence) before cryoprotectant treatment (a). After treatment of embryogenic tissue by a cryoprotectant solution (b) and immediately after thawing (c), FDA signals of embryonic cells resembled that of nontreated cells, but FDA signals of suspensor cells were plasmolysislike. After 1 day of thawing, FDA signals were emitted only by embryonic cells (d). FDA signals showing cell regrowth (arrow heads) from embryonic cells after 6 days of thawing (e). E, embryonic cells; S, suspensor cells. Scale bar $=200 \mu \mathrm{m}$. FDA, fluorescein diacetate; LN, liquid nitrogen. 


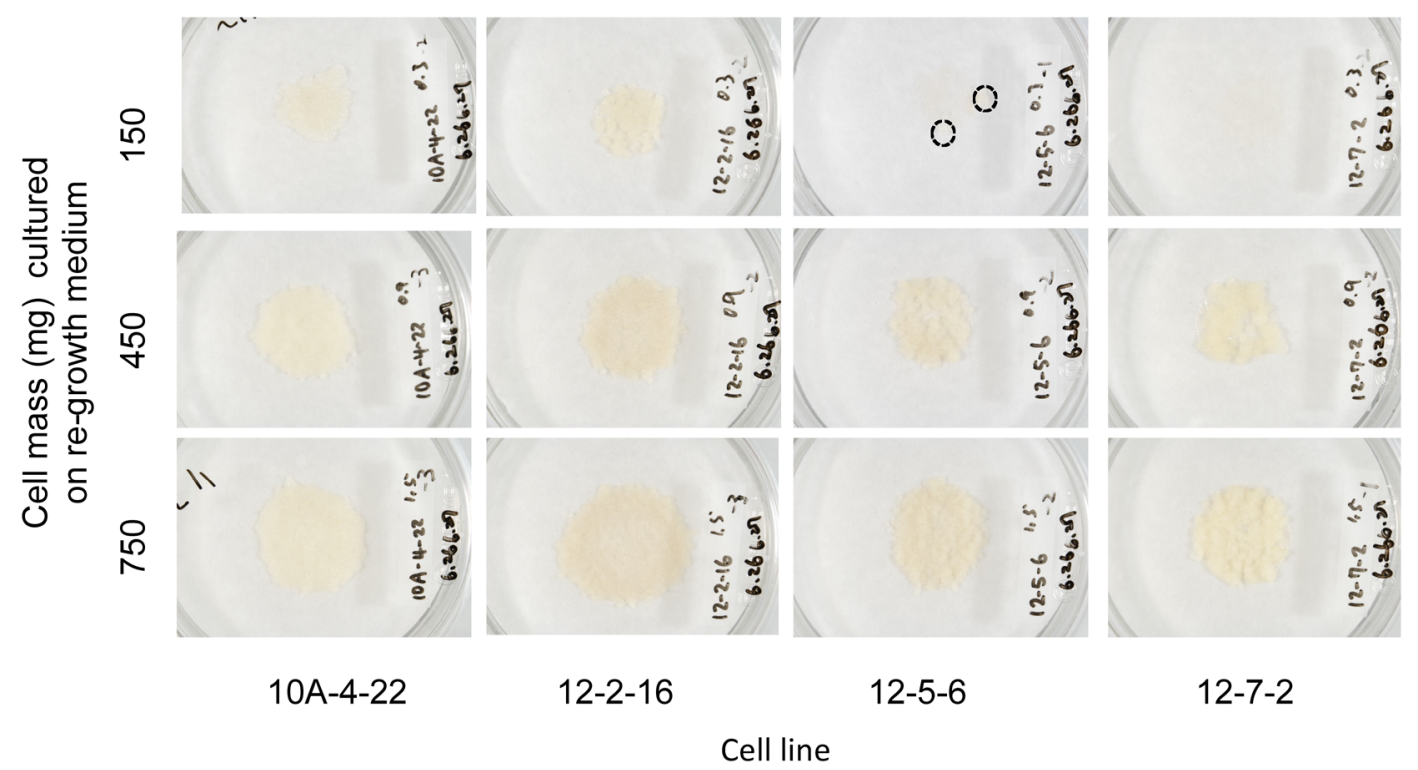

Figure 4. Effect of cell mass cultured per dish on regrowth in four cell lines of cryopreserved Cryptomeria japonica embryogenic tissue. Images were taken 4 weeks after thawing. Cryopreserved cell lines 10A-4-22 and 12-2-16 regrew successfully in 150, 450, and 750 mg cell mass. Although cell line 12-5-6 regrew slightly in $150 \mathrm{mg}$ (dotted circle) and cell line 12-7-2 did not regrow, these two cell lines regrew successfully in 450 and $750 \mathrm{mg}$. The diameter of the dishes was $9 \mathrm{~cm}$.

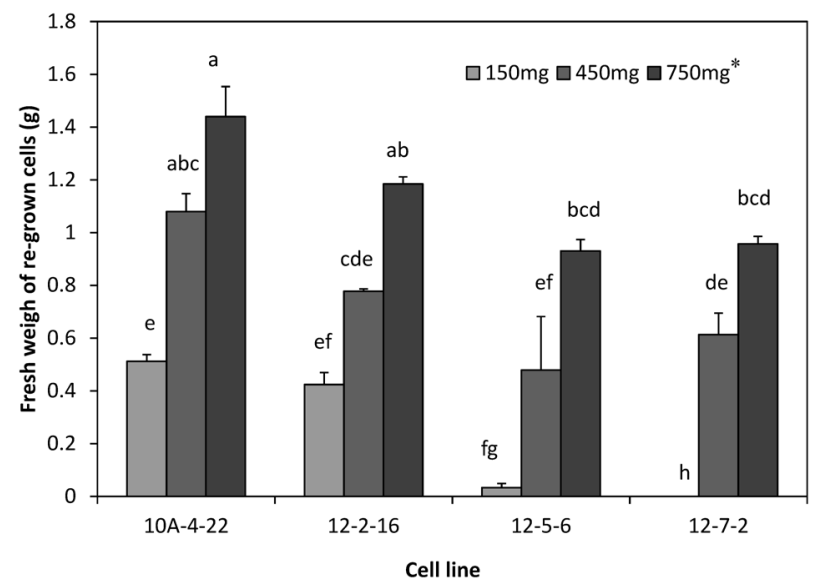

Figure 5. Fresh weight of regrown cells 4 weeks after thawing. *Cell mass cultured per dish. Vertical bars indicate standard error $(n=3)$. Different letters indicate significant differences between treatments at $p<0.05 \%$ (Tukey-Kramer test).

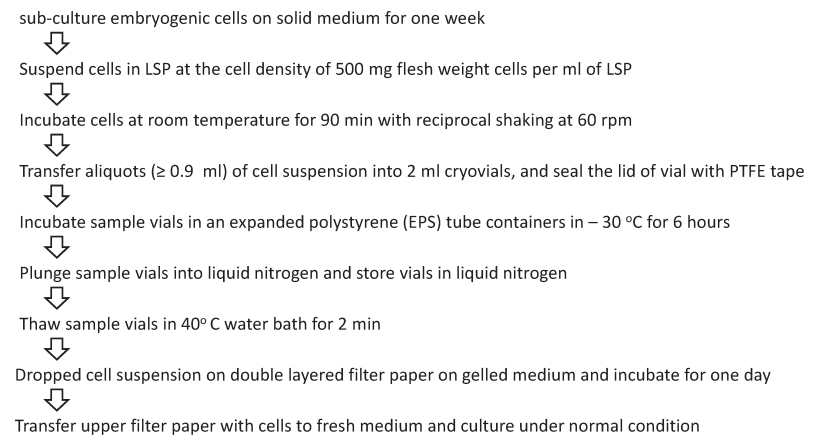

Figure 6. Protocol of embryogenic tissue cryopreservation in Cryptomeria japonica. sample vials were plunged into liquid nitrogen.

At preliminary experiment using this protocol of Ogawa et al. (2012), we examined cell viable by FDA staining before and after cryopreservation. As mentioned above, embryogenic tissue is consisted two type cells, one is small and dense embryonic cells, another is long vacuolated suspensor cells. Both two type of cells emitted green fluorescent FDA signal before cryoprotection treatment (Figure 3a). In embryonic cells, FDA signal emitted in cryoprotection treatment and after cryopreservation (Figure 3). In suspensor cells, however, FDA signal showed plasmolysis-like in high osmolality cryoprotectant treatment (Figure $3 \mathrm{~b}$ ) and slight FDA signal was emitted immediately after thawing (Figure $3 c$ ), and no FDA signal one day after thawing (Figure 3d). These results indicated that only embryonic cells are viable after cryopreservation, like in other conifer embryogenic tissues (Laine et al. 1992; Salaj et al. 2012). Six days after thawing, regrowth of cells was recognized (Figure 3e).

When $150 \mathrm{mg}$ cell mass $(0.3 \mathrm{ml}$ cell suspension) was cultured in a regrowth medium, 15 of 20 cell lines showed regrowth after thawing. This $75 \%$ success frequency was comparable to that of Pinus nigra (Salaj et al. 2012). To increase the frequency of success, we examined effect of the cell mass on re-growth of cryopreserved cells (Figures 4 and 5). The cell lines 10A4-22 and 12-2-16 regrew in $150 \mathrm{mg}$ treatment. However, the two recalcitrant cell lines 12-5-6 and 12-7-2 regrew slightly or did not regrow in $150 \mathrm{mg}$ treatment. Cell lines 12-5-6 and 12-7-2 regrew well when the cell mass increased to 450 or $750 \mathrm{mg}$. Therefore, the appropriate 

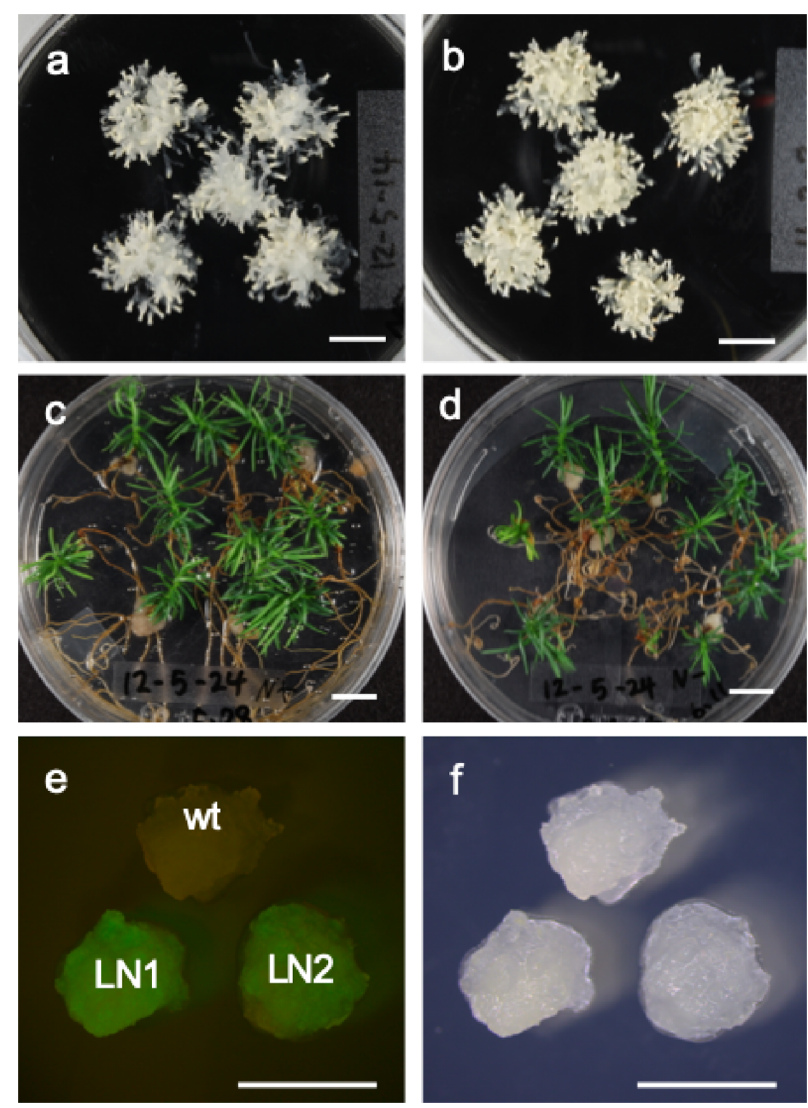

Figure 7. Somatic embryogenesis, plantlet regeneration, and genetic transformation in cryopreserved Cryptomeria japonica embryogenic tissue. Mature somatic embryos were formed from cryopreserved (a) and non-cryopreserved embryogenic tissue (b), and plantlets were regenerated from embryos derived from cryopreserved (c) and noncryopreserved embryogenic tissue (d). The $g f p$ gene was expressed in transgenic cells obtained by gene transformation into cryopreserved cells (e, fluorescent image; $f$, bright-field image). Wt, non-transformed embryogenic tissue; LN1, transformed cell line obtained by gene transformation into cryopreserved cells; LN2, embryogenic tissue obtained by cryopreserving and thawing the transformed cell line (LN1). Bars indicate $1 \mathrm{~cm}$ in $\mathrm{A}, \mathrm{B}, \mathrm{C}$, and $\mathrm{D}$ and $5 \mathrm{~mm}$ in $\mathrm{E}$ and $\mathrm{F}$.

cell mass cultured on a regrowth medium after cryopreservation is $450 \mathrm{mg}$ (i.e., $0.9 \mathrm{ml}$ cell suspension) or more. Using this protocol (Figure 6), 28 cell lines were conducted for cryopreservation, of which 27 cell lines (96.4\%) were successfully cryopreserved.

\section{Embryogenesis, plant regeneration, and genetic transformation in cryopreserved cells}

Embryogenic tissue, which was regrown from cryopreserved cells and then proliferated on 1/2 MD subculture medium, formed somatic embryos in COM medium (Figure 7a). These somatic embryos germinated and converted normally to plantlets in a germination medium (Figure 7c). These results indicated that there is no obvious difference in embryogenesis ability and plantlet formation between cryopreserved and noncryopreserved cells (Figure 7a-d). In addition, transgenic cells, which were obtained from cryopreserved cells by
Agrobacterium-mediated transformation, expressed $g f p$ (LN1 in Figure 7e). Cryopreserved transgenic cells also expressed $g f p$ (LN2 in Figure 7e). These results revealed that cryopreserved tissues can be used for genetic transformation and that cryopreservation does not affect gene expression.

\section{Conclusion}

In this study, we surveyed somatic embryogenesis potential of 2nd generation plus trees in C. japonica and selected good cell lines with high somatic embryogenesis potential, which are good target materials for genetic engineering in C. japonica. We also established a simple cryopreservation protocol for $C$. japonica embryogenic tissues that enables regrowth of most of the cell lines. Using the protocol, we created a cryopreserved cell bank of 2 nd generation plus trees. This cell bank comprises embryogenic cell lines with high somatic embryogenesis ability and will be helpful for adding useful traits, such as no-pollen, good timber quality, and fast growth, to superior C. japonica trees by molecular breeding, that is, genetic transformation and genome editing.

\section{Acknowledgements}

This research was supported, in part, KAKENHI Grant-in-Aid for Scientific Research (B), Grant/Award Number: 16H04942. The authors grateful to Ms. T. Okuyama, Ms. K. Ohubu, and Ms. J. Orita, for their laboratory assistance.

\section{References}

Breton D, Harvengt L, Trontin JF, Bouvet A, Favre JM (2006) Longterm subculture randomly affects morphology and subsequent maturation of early somatic embryos in maritime pine. Plant Cell Tissue Organ Cult 87: 95-108

Forest Tree Breeding Center (2017) Status and Statistics in Forest Tree Breeding, 2016. Forest Tree Breeding Center, FFPRI (in Japanese)

Häggman HM, Ryynänen LA, Aronen TS, Krajnakova J (1998) Cryopreservation of embryogenic cultures of Scots pine. Plant Cell Tissue Organ Cult 54: 45-53

Jain S, Gupta P, Newton R (1995) Somatic Embryogenesis in Woody Plants, Vol. 3. Kluwer, Dordrech

Konagaya KI, Kurita M, Taniguchi T (2013a) High-efficiency Agrobacterium-mediated transformation of Cryptomeria japonica D. Don by co-cultivation on filter paper wicks followed by meropenem treatment to eliminate Agrobacterium. Plant Biotechnol 30: 523-528

Konagaya KI, Kurita M, Tsubomura M, Hirao T, Watanabe A, Ishii $\mathrm{K}$, Taniguchi $\mathrm{T}$ (2013b) Induction of male sterility in transgenic sugi (Cryptomeria japonica) by barnase/barstar system. IUFRO Tree Biotechnology 2013

Laine E, Bade P, David A (1992) Recovery of plants from cryopreserved embryogenic cell suspensions of Pinus caribaea. Plant Cell Rep 11: 295-298

Nagaya S, Kawamura K, Shinmyo A, Kato K (2009) The HSP terminator of Arabidopsis thaliana increases gene expression in 
plant cells. Plant Cell Physiol 51: 328-332

Nakae K, Baba K (2010) Update on epidemiology of pollinosis in Japan: Changes over the last 10 years. Clin Exp Allergy Rev 10: 2-7

Niskanen A-M, Lu J, Seitz S, Keinonen K, von Weissenberg K, Pappinen A (2004) Effect of parent genotype on somatic embryogenesis in Scots pine (Pinus sylvestris). Tree Physiol 24: 1259-1265

Ogawa Y, Sakurai N, Oikawa A, Kai K, Morishita Y, Mori K, Moriya K, Fujii F, Aoki K, Suzuki H, et al. (2012) High-throughput cryopreservation of plant cell cultures for functional genomics. Plant Cell Physiol 53: 943-952

Park YS (2002) Implementation of conifer somatic embryogenesis in clonal forestry: Technical requirements and deployment considerations. Ann Sci 59: 651-656

Park YS, Pond SE, Bonga JM (1994) Somatic embryogenesis in white spruce (Picea glauca): Genetic control in somatic embryos exposed to storage, maturation treatments, germination, and cryopreservation. Theor Appl Genet 89: 742-750

Sakai A, Kobayashi S, Oiyama I (1991) Cryopreservation of nucellar cells of navel orange (Citrus sinensis Osb.) by a simple freezing method. Plant Sci 74: 243-248
Salaj T, Matušíková I, Swennen R, Panis B, Salaj J (2012) Longterm maintenance of Pinus nigra embryogenic cultures through cryopreservation. Acta Physiol Plant 34: 227-233

Taniguchi T, Konagaya K, Kurita M, Ishii K (2012) Somatic embryogenesis from artificial crossed immature seed in Cryptomeria japonica plus trees. Annual Report Forest Tree Breeding Center 2011: 88-90 (in Japanese)

Taniguchi T, Kondo T (2000) Difference in the ability of initiation and maintenance of embryogenic cultures among Sugi (Cryptomeria japonica D. Don) seed families. Plant Biotechnol 17: $159-162$

Taniguchi T, Kurita M, Itahana N, Kondo T (2004) Somatic embryogenesis and plant regeneration from immature zygotic embryos of Hinoki cypress (Chamaecyparis obtusa Sieb. et Zucc.). Plant Cell Rep 23: 26-31

Taniguchi T, Ohmiya Y, Kurita M, Tsubomura M, Kondo T (2008) Regeneration of transgenic Cryptomeria japonica D. Don after Agrobacterium tumefaciens-mediated transformation of embryogenic tissue. Plant Cell Rep 27: 1461-1466

Widholm JM (1972) The use of fluorescein diacetate and phenosafranine for determining viability of cultured plant cells. Stain Technol 47: 189-194 